Tetrahedron Letters No.12, pp. 1529-1532, 1968. Pergamon Press. Printed in Great'Brituin.

\title{
CALCULATION OF CARBON-SULPHUR BOND LENGTHS
}

$$
\text { N. Trinajstic }
$$

Institute "Rudjer Boškovié", Zagreb, Croatia, Yugoslavia

(Received in UK 18 November 1967)

It is possible to calculate bond lengths from the known bond orders. But, for that it is necessary to establish a relatioship between bond length and bond order. Such a relationship has been established for the case of $\mathrm{C}-\mathrm{C}$ bonds (1-3), and works quite well (4). There were several attempts in the past $(5,6)$ to establish the bond length-bond order relationship for C-S bonds. Previous research workers have used HMO bond orders, and they have also assumed that the length of a double $\mathrm{C}-\mathrm{S}$ bond $1 \mathrm{~s} 1.61$ \&. It appears that this value is a little too long for a double $\mathrm{C}-\mathrm{S}$ bond (7): In this communication we present a new bond length-bond order curve, which differs from previous ones because we have used SCF bond orders, and we have taken more realistic value for the length of a double $\mathrm{C}-\mathrm{S}$ bond. For single and double $\mathrm{C}-\mathrm{S}$ bonds average values of $1.82 \AA(7)$ and $1.56 \AA(7)$ respectively, are used. Our curve for the dependence of C-S bond length on double bond character is given in the Fig. The following linear equation could approximate this curve :

$$
L(i j)=1.82-0.26 \mathrm{p}(i j)
$$

where $L(i j)$ is a bond length in $\AA$, and $p(i j)$ is calculated bond order. 


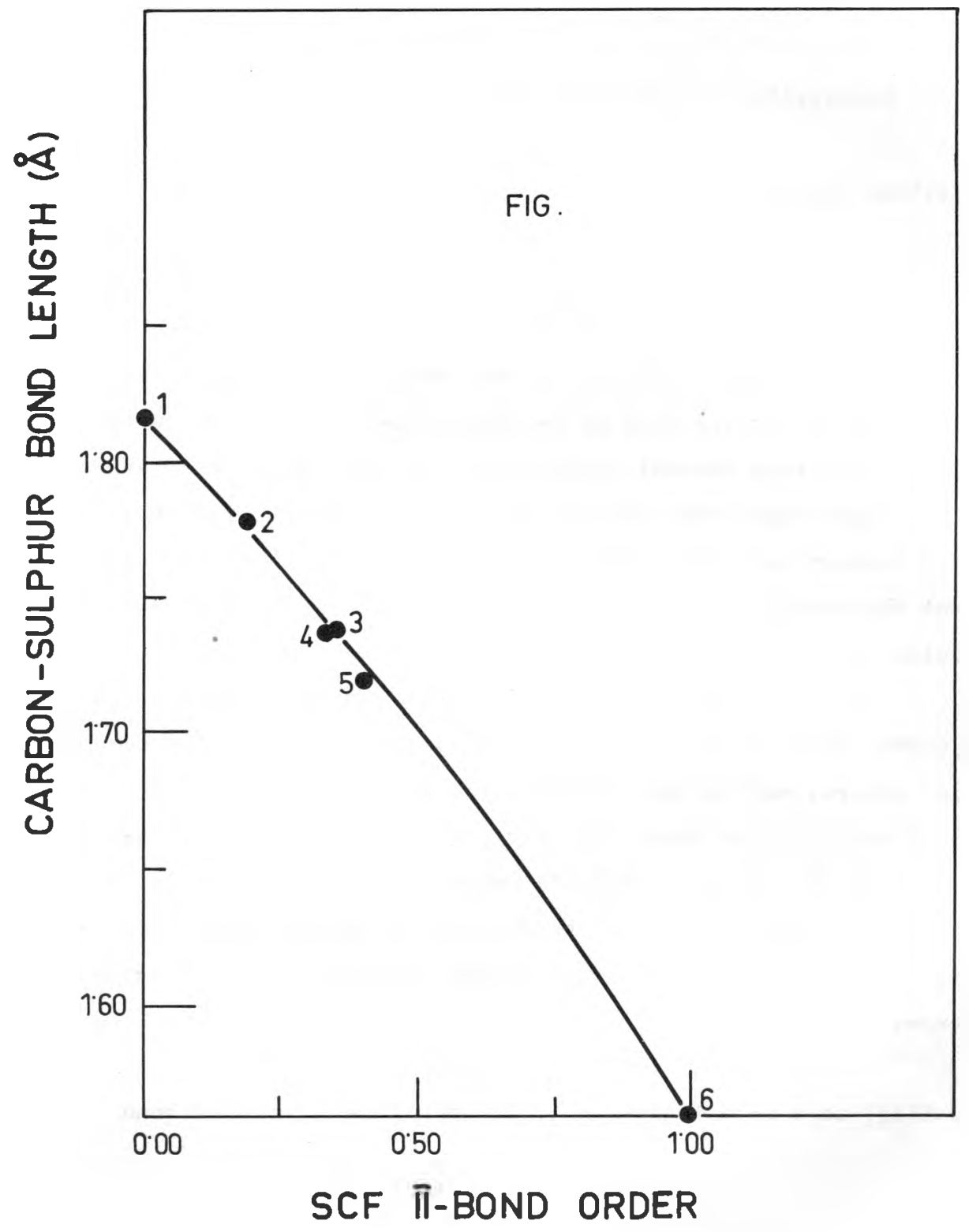


SCF $\pi$-bond orders and experimental and calculated values for $C-S$ bond lengths are given in the Table.

\section{TABLE}

Comparison of Calculated and Observed Bond Lengths for $c\left(s p^{2}\right)-s(I I)$ Bonds

No. of Compounds point in the Fig.
Observed C-S SC bond length order in $\AA$
Calculated $\mathrm{C}-\mathrm{S}$ bond length in $A$ from the Iinear relationship (I)

1. peraffinic $\mathrm{C}-\mathrm{S}$

bond (average

$$
\text { value) }
$$

0.00

1.82

2. 1,4-dithiene

1.78 (8)

0.19 (9)

1.77

3. $i$

1,4-thiophthene

$$
1.74 \text { (10) }
$$

0.36 (II)

1.73

5.

1.72 (10)

0.41

1.71

4. thiophene

1.74 (12)

0.34 (9)

1.73

6. double $\mathrm{C}-\mathrm{S}$ bond (average.value)

The agreement between the calculated and observed values is quite good. Slight differences (of the order of 0.01 \&) are due to the fact that we have adopted the linear relationship while our curve shows a little curvature. 
REFERENCES

1. C. A. Coulson, Proc. Roy. Soc. A 169, 413 (1939).

2. C. A. Coulson and A. Golebiewski, Proc. Phys. Soc. 78, 1310 (1961).

3. D. W. J. Cruickshank and R. A. Sparks, Proc. Roy. Soc. A 258 . 270 (1960).

4. G. V. Boyd and N. Singer, Tetrahedron 22. 3383 (1966).

5. S. C. Abrahams, Quart. Rev. 10. 407 (1956).

6. A. Hordvik and E. Sletten, Acta Chem. Scand. 20, 1938 (1966).

7. Tables of Interatomic Distances, Special Publication No. 18, Cremical Society, London 1965.

8. P. A. Howell, R. M. Curtis, W. N. Ifpscomb, Acta Cryst. I, 498 (1954).

9. D. S. Sappenfield and M. Kreevoy, Tetrahedron $\underline{\underline{19}}$ (Suppl. 2), 157 (1963).

10. M. G. Evans and J. de Heer, Acta Cryst. 2, 363 (1949).

11. N. Trinajstic and A. Hinchliffe, Croat. Chem. Acta 39. 119 (1967).

12. V. Schomaker and I. Pauling, J.Am. Chem. Soc. 6l, 1769 (1939). 